\title{
LA XARXA VIÀRIA CATALANA A LALTA EDAT MITJANA. UNA APROXIMACIÓ DES DE LA CARTOGRAFIA
}

\author{
JORDI BOLOS \\ Universitat de Lleida \\ VÍCTOR HURTADO \\ Universitat de Barcelona
}

\begin{abstract}
SUMARI
Introducció.- A. Les "vies francisques".- B. Les vies de la sal. Les "estrades cardoneses".- C. Vies i mercats.- D. Vies i mercaders.- E. Camins i dominis monàstics.- $F$. Camins i rotlles mortuoris.- G. Fortificacions i vies.- H. Camins, pobles i masos.- I. Camins i límits parroquials.- J. Camins i partions de camps.- K. Camins i membres d'una confraria.- L. Vies i antropònims.
\end{abstract}

\section{INTRODUCCIÓ}

Podem apropar-nos als camins medievals amb diverses perspectives. Podem veure els camins com unes vies de comunicació per les quals viatjaven els reis, els comtes, els bisbes i abats; els podem veure com unes vies de penetració dels exèrcits $i$ de les invasions o bé com a camins de pelegrinatge que permetien que els romeus de qualsevol país anessin a Roma, a Sant Jaume de Galícia, a Conques (Occitània) o, fins i tot, a Terra Santa; els podem veure, també, i sobretot, com unes vies comercials, per les quals transitaven mercaders amb llurs atzembles carregades de mercaderies o com un lloc de pas que permetia de comunicar indrets i per on també passaven pagesos o repobladors. Via de comunicació en primer lloc, el camí pot ésser també estudiat per la freqüència o per la intensitat amb què era utilitzat. Descobrim així els eixos més importants de la xarxa viària bàsica, a partir de la qual podem classificar els itineraris en principals o en secundaris. Malgrat les diferències, aquestes diverses visions coincideixen en el fet d'estudiar el camí per ell mateix, com un mitjà, i independentment del seu entorn. 
Una altra manera d'apropar-nos al coneixement de les vies és considerar-les com a part integrant d'un paisatge. En un cert sentit, passem de l'anàlisi de grans o mitjans territoris a l'anàlisi d'un espai limitat. El camí és un element més d'un paisatge que ens pot envoltar en un cert moment $\mathrm{i}$ que, per tant, cal relacionar amb els altres elements d'aquest paisatge; resta influit pels restants components de l'entorn $i$, al mateix temps, influeix en aquests elements del seu voltant. Qualsevol via es pot relacionar doncs amb uns pobles, unes senyories, uns camps, uns molins, etc. L'existència o no de qualsevol d'aquests elements afecta el camí i el camí, al seu torn, pot afectar tots aquests altres elements.

Una tercera manera d'apropar-nos als camins és a través de mitjans arqueològics. Ens podem posar a estudiar les mides dels camins, les característiques dels seus marges, del seu paviment, del sòl rocós per on passa, dels seus ponts, etc. Podem estudiar-ne l'itinerari i veure com canvien les seves característiques. Hom pot intentar fer una tipologia de camins: camins amb un sòl de pedra on es graven les roderes, camins empedrats amb pedres o còdols de formes i mides diverses, camins amb un marge lateral d'obra de pedra seca, camins enclotats entre camps, etc.

Ara, però, no desitgem pas entrar en aquest aspecte. Ens volem centrar, més aviat, en aquells aspectes que poden ésser traslladats sobre una base cartogràfica i permetre l'elaboració d'un mapa que doni, per exemple, una visió de conjunt de tota la xarxa viària. Per tant, ens preocuparem del camí com a via de comunicació $i$, secundàriament, del camí com a element del paisatge.

D'entrada, abans de posar-nos a estudiar aspectes concrets, hem de dir que en analitzar els camins medievals cal tenir-ne ben present un aspecte: en bona part són herència del passat romà ( $i$, en algun cas, fins $i$ tot, de vies d'època anterior). Per això, cal ésser conscient que estudiar els camins de l'alta edat mitjana és bàsicament estudiar camins romans.

A més, deixant de banda aspectes arqueològics, podem fer una doble classificació de les vies, en funció de la finalitat bàsica que té un camí determinat $\mathrm{i}$ en funció de la terminologia emprada als documents medievals a l'hora de designar-lo. Amb tot, som conscients que potser caldria fer una classificació prèvia entre vies terrestres, fluvials i marítimes; nosaltres ens centrarem, en aquest estudi, clarament en les terrestres.

Pel que fa a la finalitat de les vies, podem parlar de camins que unien terres llunyanes (per exemple, les vies «francisques» que esmentarem més avall), de camins que tenien un abast comarcal (per exemple la via que anava de Peralada a Besalú), de camins que permetien anar d'una parròquia a una altra (xarxa viària que s'estenia per tot el territori, segurament de creació medieval) i, finalment, de camins destinats a poder anar als camps, a les vinyes, a l'hort, al bosc, a la font o a la bassa (creats al mateix moment que 
es romperen els camps, es feren els horts o els vinyets i s'organitzà el poblament concentrat o dispers). ${ }^{1}$

En relació amb la terminologia emprada als documents, cal dir que bàsicament, abans de l'any 1000 , s'hi fan servir tres noms que, com és lògic, reflectien tres conceptes poc o molt diferenciats: l'estrada (strata), la via (via) i el sender (semitario). La confusió entre estrada i via s'esdevé molt sovint; no sabem pas fins a quin punt podem compartir la diferenciació que fan els anglesos entre la via (weg) amb un origen antic, potser anterior a l'època romana, i l'estrada (straet) de tradició romana. ${ }^{2}$ El que sí que sembla evident és que el sender tenia una mida diferent i tenia una finalitat $i$, potser, una tradició també diversa.

$A$ aquests termes bàsics, cal afegir-hi encara esments d'altres termes menys usuals, de vegades relacionats amb les característiques del camí, com poden ésser els de calçada (calciata), carrera (carraria) i els més genèrics iter, camí (caminum), etc. Així mateix, algunes vegades, com ho veurem més endavant, el nom via o estrada va acompanyat d'un adjectiu que permet de definir-ne més bé les característiques: via antiqua, via carrale, charraria vetere, via kalciata, magna strata, via merchadal, stratam regiam, via tabernaria, iter publicum, etc., o que, molt sovint, ens permet de saber on va: via cerdana, viam roedana, strata francisca, strada cardonesa, strada manresana, strata bergitanense, viam ausonensem, etc. ${ }^{3}$

\section{$* * *$}

A continuació mostrarem diferents possibles formes d'apropar-nos al coneixement dels camins medievals, d'una manera directa o de vegades indirecta. Evidentment ens mourem dins del marc que hem establert més amunt; és a dir no farem cap esment de treballs o prospeccions arqueològiques. Som conscients, però, de la importància que tindria, de cara al coneixement de les vies medievals, la realització d'estudis profunds -fets amb documents i/o amb treball de camp- d'àmbits limitats (parròquies o municipis) per tal de poder arribar a resoldre alguns punts foscos de la xarxa vià-

1 Vegeu: Michael Aston, Interpreting the Landscape. Landscape Archaeology in Local Studies, Londres, 1985, pp. 143-146.

${ }^{2}$ Della Hooke, The Anglo-Saxon Landscape. The Kingdom of the Hwicce, Manchester, 1985 , pp. 145-147.

3 Per a fer aquest article, $i$ en especial aquest paràgraf introductori, hem utilitzat les dades de: Jordi Bolos, Aportacions al coneixement de les vies de comunicacio, «Symposium Internacional sobre els Orígens de Catalunya (segles viII-XI)», Barcelona, 1991, pp. 409436. Vegeu també: Jordi Bolos, Els camins de la Catalunya medieval, «Finestrelles», III (1991), pp. 117-131. 
ria però també, per evitar que es perdi una informació que ha arribat fins a l'actualitat i que molt aviat serà difícil de conèixer, a causa de les transformacions esdevingudes al món rural, sobretot durant la segona meitat d'aquest segle $x x$, en abandonar-se zones senceres, especialment a les comarques de muntanya, fet que comporta la desaparició material de molts camins i, fins i tot, que se'n perdi el record.

\section{A. LES «VIES FRANCISQUES»}

La historiografia catalana tradicional havia considerat que només hi havia una "via francisca", i que aquest nom, a l'alta edat mitjana, tan sols era aplicat a un gran camí, de tradició romana, que anava de Barcelona a la terra dels francs. ${ }^{4}$ Darrerament, en poder disposar de més documentació, hom ha pogut comprovar que la realitat no era pas tan senzilla i que hi havia diverses vies «francisques", tantes com camins importants que anaven cap al nord, això és, cap a França. En podem veure uns quants exemples:

- stratam franciscam (958, al Conflent)

- strata francisca superiore (885, a l'Alta Cerdanya)

- strata francisca (978, Cerdanya, Ger)

- strata via francischa (1070, Cerdanya, Alp)

- strada franciska (965, Osona, Crivillers)

- strada francisca (982, Osona)

- strada francescha (980, Osona)

- strada francisca (965, Osona, Sant Sadurní d'Osormort)

- via francisca (917, Vallfogona de Ripollès)

- strada quae dicitur francigena (1075, Garrotxa, a l'est de Besalú)

- via franchesca qui discurrit ad Impurias civitate (913, Empordà, al nord d'Empúries)

- strada francisca (976, Empúries, al sud de Figueres)

- strada francisca (1007, Gironès, Cervià)

- strata francisca (1022, la Selva, per sota el Montseny)

- strata francisca (1159, Vallès Oriental)

- stratam publicam que dicitur franzescha (1154, Vallès Oriental, Reixac, al nord de Barcelona)

${ }^{4}$ Així encara és acceptat per P. BonNassie, Catalunya mil anys enrera (segles $X-X I$ ), I, Barcelona, 1979, p. 319. Abans, fins $i$ tot, molts historiadors arribaren a considerar que conèixer la «via francisca» podia permetre de saber quin havia estat el camí seguit pels exèrcits francs. Vegeu l'estudi, d'altra banda molt ben documentat i minuciós, J. BALARI I Jovany, Orígenes bistóricos de Cataluña, Barcelona, 1899, pp. 291-298. 
- via francisca (1002, Barcelonès, Magòria, ciutat actual de Barcelona)

- via francisca (996, Barcelonès, Sant Andreu de Palomar)

- ipsa calciata francischa (978, Penedès, cap a Olèrdola). ${ }^{5}$

Veiem que aquests vies dels francs podien sortir de Barcelona o de Girona, però també de Vic, de la Cerdanya o d'Empúries. De fet, cal tenir present que, al costat de les vies dels francs, també hi havia vies que permetien d'anar a les terres controlades pels musulmans. Així, sembla que, l'any 1046, surt un esment d'una strata morischa, al Penedès.

\section{B. Les VIES DE LA SAL. LeS «ESTRADES CARDONESES»}

La sal era un producte indispensable a l'edat mitjana, d'una manera especial de cara a la conservació dels aliments. A Catalunya, com a tot arreu, hi havia tres maneres d'obtenir sal, ja abans de l'any 1000: a partir de l'extracció del mineral, a partir de l'evaporació de l'aigua d'una deu o font i a partir de l'evaporació de l'aigua del mar. Els principals indrets on hom podia obtenir aquest producte eren Cardona, amb la seva coneguda muntanya de sal, aleshores entre els comtats d'Urgell i de Manresa, el lloc de Gerri de la Sal, al comtat del Pallars, i, finalment, també a tota la zona de la costa, especialment al litoral del Rosselló. ${ }^{6}$

Ja en documents d'abans de l'any 1000 es fa esment de les eres de sal (areas) o dels salins (salectis) del monestir de Gerri de la Sal. ${ }^{7}$ Un acurat estudi publicat sobre aquesta abadia ens mostra que, a partir de Gerri, devia sortir una xarxa de camins que anaven cap a Sort, cap a Tremp i cap a la Vall de Cabdella, pel Pla de Corts, o cap a la Seu d'Urgell, per Sobre Gerri i per la vall de Taús i Cabó etc. ${ }^{8}$ La xarxa de distribució de la sal d'aquest lloc s'estenia per les comarques veïnes i fins i tot arribava a l'altra banda dels Pirineus, com resta reflectit en un document de l'any 1176 , on s'estableix la donació que el comte Artau IV de Pallars i la seva 430-435.

5 Vegeu les referències a: J. Bolos, Aportacions al coneixement de les vies de comunicació, pp.

${ }^{6} \mathrm{La}$ importància dels indrets on es produïa sal a l'edat mitjana i la repercussió que això tenia sobre la xarxa de vies de comunicació ja han estat estudiades en relació amb d'altres països, per exemple, Anglaterra, pel que fa al cas de Droitwich. Della Hooke, Op.cit., p. 125; H.C. DArby, Domesday England, Cambridge, 1986, p. 262; R.H. Hilton, A Medieval Society. The West Midlands at the End of the Thirteenth Century, Cambridge, 1983, p. 11.

7 Ramon D'ABADAl, Els comtats de Pallars i Ribagorga, Barcelona, 1955, doc. 200 (any 966).

${ }^{8}$ Ignasi PUIG I Ferrete, El monestir de Santa Maria de Gerri (segles XI-XV), I, Barcelona, 1991, pp. 375-380. 
muller Guillema havien de fer, cada any, de 10 muigs de sal de Gerri al monestir occità de Sant Llorenç de Comballonga, a Coserans. ${ }^{9}$

Diversos camins anaven a les salines de la costa del Rosselló, tal com ho trobem a la mateixa documentació. ${ }^{10}$ Tot i que no surti tan ben documentat, cal pensar que a les costes, per exemple, dels propers comtats de Peralada i d'Empúries, on hi havia importants zones d'aiguamolls, també hi hauríem trobat àrees destinades a obtenir sal a partir de l'aigua marina.

Cardona era una ciutat molt desitjada pels cristians per la seva situació estratègica, aigües amunt del Cardener, però també per la muntanya de sal, cèlebre ja en època romana. En temps de Carlemany, aquesta població ja és fortificada i fa d'extrem meridional de la línia controlada pels francs, fins $\mathrm{i}$ tot abans de la conquesta de Barcelona del 801. Més tard, fou ocupada i repoblada en època del comte Guifre I i del comte Borrell de Barcelona. ${ }^{11}$

Ara però, volem cridar l'atenció, d'una manera especial, sobre el fet que de la ciutat de Cardona sortien pels volts de l'any 1000, d'acord amb la documentació, una sèrie de camins que s'estenien radialment tot a l'entorn i que tots plegats rebien el nom de vies o estrades "cardoneses", cosa que no trobem d'una manera tan clara, per exemple, ni a Vic ni a Girona ni, fins $\mathrm{i}$ tot, a Barcelona, tot i que, com a ciutats velles també eren al centre d'una xarxa radial de camins. Fixem-nos en quines vies hi havia:

- cap a Berga: strata kardonense (922), strata de Cardona (899)

- cap a Solsona: strata cardonense (977)

- cap a Manresa: strada cardosenaria (996). ${ }^{12}$

\section{VIES I MERCATS}

Les activitats econòmiques es desenvolupen sempre al llarg de les vies de comunicació. Com és lògic, els molins fariners, les fargues, els forns de calç o de ceràmica $o$, fins $i$ tot, els indrets on es feien les activitats agrícoles -com ho veurem més endavant en parlar dels camps- necessitaven que hi passés a prop una via. És, però, sense cap mena de dubte, l'activitat comercial, i concretament la situació dels mercats, la més condicionada per la xarxa viària. Joan Vilà Valentí afirma, encertadament, que durant bona part

9 I. Puig I FerretE, Op.cit., vol. I, pàg. 379. També: vol. II, doc. 164.

${ }^{10}$ R. LaCvivier, Le cartulaire de l'église d'Elne, "Ruscino» (1913), pp. 175-193, 319$352,471-485$.

11 De l'època d'aquest segon comte es conserva una notable carta de poblament (any 986). J.M. FONT RiUs, Cartas de población y franquicia de Cataluña, I, Madrid-Barcelona, 1969, doc. 9.

${ }_{12}$ Vegeu-ne les referències a: J. BoLos, Aportacions al coneixement de les vies de comunicacio, pp. $430-435$. 
de l'edat mitjana, quan els nuclis de poblament eren relativament poc importants, els mercats se situaven no sols tocant a les poblacions importants, sinó també a la cruilla dels camins o a les voreres de les vies més freqüentades. ${ }^{13}$

Així doncs, sembla que, a l'alta edat mitjana, els mercats eren situats als afores de les ciutats més importants de l'època (Barcelona, Girona, Elna, Vic, Besalú, Manresa, Cardona, la Seu d'Urgell, Berga, etc.). De vegades, també al costat de grans monestirs, com Ripoll o Banyoles (generalment molt ben situats) o bé, potser més tard, Camprodon i Arles. A més, i ara és el que ens interessa d'una manera especial, en cruilles de camins o al costat de vies importants. Un cas molt clar d'això el trobem a Martorell, on l'any 1032 és mencionat un foro Martorelio, que molt probablement fa referència a un mercat que se celebrava en aquesta població propera al Llobregat. També es desenvolupà aviat, en un moment pròxim a l'any 1000 , un altre centre de mercaders al Vallès oriental on es creuaven les vies que venien de Girona i de Martorell amb les que provenien de Vic i de Barcelona. Ja l'any 1019 , trobem que a Montornès del Vallès s'esmenta l'existència d' ipsum mercatum i, cap al 1041, és mencionat un mercat de Granollers. Així mateix, també es degué crear un mercat en algunes de les poblacions de l'Empordà, on es creuaven les vies que anaven de les terres dels francs a Barcelona amb els camins que, des la costa, anaven a l'interior, cap a Besalú. Tot $\mathrm{i}$ que a Bàscara o a Monells no trobem documentada l'existència d'un mercat fins als anys 1187 i 1104 , respectivament, segurament llurs orígens els hauríem de cercar en un moment més proper a l'any 1000. Un altre indret que, observant el mapa, veiem que podia ésser un lloc adequat per a establir-hi un mercat és la Cerdanya, on confluièn diverses vies provinents del Rasès (Occitània), del Conflent, de l'Alt Urgell, del Ripollès, del Berguedà, etc. Així, vers l'any 1075, s'esmenta l'existència d'un forum Exii, a la població d'Ix. ${ }^{14}$ Segurament també tenia una ubicació semblant el mercat (ipso Mercadale) que hi havia, almenys des l'any 950, a l'extrem meridional de la vall d'Àneu (Pallars), a la confluència entre les vies que anaven cap a Occitània $\mathrm{i}$ les que venien del sud o les que anaven cap a la Vall Ferrera o vers ponent. ${ }^{15}$ També, com en tots els altres casos, podem pensar que, d'una banda, es triava un indret on es podia arribar facilment des de diversos llocs, ja que hi coincidien nombroses vies, però

13 Joan ViLג I VALenti, El món rural a Catalunya, Barcelona 1973, pp. 52-53 (en el capítol dedicat a "Vida rural i mercats setmanals els segles $\mathrm{X}$ al XII»).

14 Vegeu les referències incloses en el llibre de Vilà i Valentí esmentat a la nota precedent. Vegeu també: P. BonNassie, Catalunya mil anys enrera (segles X-XI), Barcelona, 1979, pp. 320-322.

is R. D'ABADAl, Els comtats de Pallars i Ribagorga, Barcelona, 1955, doc. 162. 
que, de l'altra, de fet, s'hi anava creant un cert mercat comarcal o subcomarcal. Un paper semblant, mercat d'una contrada i lloc de confluència de vies i de gents, l'hauríem trobat en el mercat de Corts, a ponent de Gerri de la Sal, ja documentat al segle XI. ${ }^{16}$

Per desgràcia, en general i a tot arreu, la documentació és tan escassa $\mathrm{i}$ la trobada de les dades que tenim és tantes vegades fruit de la casualitat, que hom té la impressió que només ens acostem al coneixement del fenomen de la creació dels mercats i, sobretot, al coneixement de la seva cronologia. ${ }^{17}$ De fet, no té gaire sentit que hi hagués un mercat vers Llavorsí, al Pallars, a mitjan segle $\mathrm{X}$ i que, en canvi, no n'hi hagués cap a la Cerdanya a la mateixa època, a la Ribagorça, al Conflent o bé a l'Empordà, per esmentar alguns llocs. Una lògica extrapolació de dades ens hauria de fer pensar que al segle $\mathrm{X}$ o, molt sovint al segle $\mathrm{XI}$, ran del creixement econòmic que hi hagué en aquest moment estudiat magistralment per $\mathrm{P}$. Bonnassie, es creà una xarxa ja força atapeïda de petits mercats comarcals i subcomarcals.

\section{VIES I MERCADERS}

Les mercaderies, com els mercaders, sempre es desplacen per la xarxa viària, cercant sobretot la seguretat i la rapidesa en aquests desplaçaments. No ens pot pas sorprendre, doncs, que les al.lusions a mercaders les trobem precisament en els camins de màxima circulació: com segurament ho era la gran via francisca que de Girona portava cap a França i que, l'any 921, en passar prop de Bàscara, a l'Alt Empordà, també rebia el nom de viam merchaderiam. O bé, la via que travessava la Cerdanya i era anomenada, l'any 1052 , via merchadal. Així mateix, també era considerada una strata mercadera la via que de Barcelona o des del Vallès travessava el Penedès cap al sud, tal com surt en un document de l'any $1108 .{ }^{18}$ Certament, aquests tres esments no són pas ben casuals; de fet, potser ens assenyalen les tres vies més importants pel que fa al transport de mercaderies: la que anava de Narbona a la Clusa i després fins a Barcelona, passant segurament per

16 Ignasi M. PUIG I Ferreté, El monestir de Santa Maria de Gerri (segles XI-XV), I, Barcelona, 1991, pp. 380-383.

17 Mentre, d'una banda, trobem a faltar la documentació que ens citi l'existència d'alguns mercats, de l'altra, alguns dels que sembla que hi ha esmentats no és pas ben segur que existissin. Pensem, per exemple, en el documentat l'any 1017, a la parròquia de Sant Vicenç del Sallent, al municipi de Santa Pau. El fet que no hi hagi cap continuïtat fa que aquesta referència sigui molt dubtosa. Vegeu: Jordi Bolos, El mas, el pagès $i$ el senyor. Paisatge $i$ societat a la parroquia de Sant Vicens del Sallent (la Garrotxa) a l'edat mitjana, Barcelona (en curs de publicació).

18 Vegeu nota 3. 
Girona i la comarca de la Selva; la que anava de Barcelona cap al sud, passant per la cruilla de Martorell i travessant el Penedès; i la ruta pirinenca de la Cerdanya, que, venint de la conca mitjana del Segre i de la Seu d'Urgell, permetia d'anar vers el Rosselló o vers Occitània. No és doncs tampoc cap casualitat que un turó situat a l'Alt Empordà, entre Vilabertran i Peralada, rebés el nom, l'any 974, de Pugo Mercader. ${ }^{19}$

No podem pas saber de cert per on devien passar els mercaders que anaven de l'Europa septentrional a la terra dominada pels musulmans, com el casualment famós mercader Robert, documentat l'any $1009 .{ }^{20}$ Segurament, però, seguien aquesta via que anava de Salses fins al Vallès, passant per l'Empordà, Girona i, segurament, la Selva, camí molt més recte que no pas el que passava pel Ripollès i per Osona.

\section{E. CAMins I dominis monȦstics}

És prou conegut el fet que moltes vegades les donacions als monestirs per part de les autoritats de l'època eren fruit d'una petició feta per la mateixa comunitat monàstica, aspecte que, tanmateix, no sol restar reflectit a l'acte de cessió. Quan traslladem, però, les llistes de propietats que depenien d'un monestir sobre un mapa, ens adonem de la lògica de la major part dels grans dominis monàstics. Esmentem uns quants exemples, relacionats amb monestirs com Ripoll, Sant Joan de les Abadesses, Camprodon, Sant Pere de Rodes, Cuixà, Serrateix, etc.

Fixem-nos en els principals colls o llocs de pas de la Cerdanya: el coll del Pendís era controlat per l'abadia de Ripoll, que tenia terres a banda i banda de la collada (Sant Martí de Vilavedra i Ascariu); la collada de Toses era controlada per la comunitat de Sant Serni de Tavèrnoles (Umfred) i per la de Ripoll (Planès i Ventolà); les calmes del Pla d'Anyella, sobre Castellar de N'Hug, depenien del monestir de Sant Joan de les Abadesses; el coll de la Perxa depenia del monestir de Cuixà (Bolquera). Si ens fixem en el Ripollès, veiem com el pas que separava el Berguedà del Ripollès depenia també 'del monestir de Ripoll (Aranyonet, Merola); el coll per entrar al Vallespir era en mans del monestir de Camprodon (Vernedell). El nombre d'exemples encara podria ésser molt més gran. El Congost, pas estret entre Osona i el Vallès, depenia del monestir de Sant Joan de les Abadesses, que no sols tenia Aiguafreda sinó també importants drets a la Roca.

19 Vegeu: J.Bolos - V. Hurtado, Atlas Historic de Catalunya. Anys 759-992, full 111, Barcelona, 1986.

20 Philippe WolfF, Quidam homo nomine Roberto negociatore, «Regards sur le Midi médiéval», pp. 473-480. 
Aquestes evidències també ens haurien de fer pensar en el fet, ja prou conegut, que en aquesta època qualsevol domini senyorial tendia a tenir terres que li permetessin de proveir-se de cara a la seva autosuficiència. ${ }^{21}$ Per tant, el domini d'aquests colls de muntanya per part dels monestirs hem de relacionar-lo més aviat amb els camins de transhumància que no pas amb una possible creació de peatges o lleudes i hem de valorar la importància, molt poc esmentada a la documentació de l'època altmedieval, de la ramaderia en l'economia monàstica d'abans de l'any $1000 .^{22}$

Un altre aspecte -complementari d'aquest- és que, en principi, el repartiment dels dominis de qualsevol monestir havia d'ésser en funció de la possibilitat d'arribar-hi amb una certa facilitat. En veure la manera com es reparteixen aquestes possessions monàstiques ens adonem també que la xarxa de comunicacions era, en certs aspectes, molt semblant a l'actual, però, en uns altres, tenia notables diferències de base, com ho veurem tot seguit. Si ens fixem, per exemple, en el repartiment dels dominis del monestir de Sant Pere de Rodes cap a l'any 1000, veiem que sembla que giri en relació a dues bases econòmiques, a part de l'agrícola: d'una banda, el litoral amb la pesca (i potser amb algunes pastures intensives) $i$, de l'altra, les muntanyes $\mathrm{i}$ les pastures de les "calmes" o altiplans de les carenes. Malgrat això, tornant al que dèiem més amunt sobre les comunicacions, ens crida l'atenció el fet que aquest monestir empordanès tingués possessions a Llimiana, al Pallars Jussà, ${ }^{23}$ i d'altres béns a la Cerdanya, a les viles d'Ix i d'Osseja. Aquest fet demostra l'existència d'un eix de comunicacions transversal, pirinenc, que saltava d'una conca fluvial a l'altra o que seguia les carenes sense endinsar-se al llarg dels cursos dels rius. És prou sabut que, de vegades, en zones de muntanya han tingut, quasi fins a l'actualitat, més pes els camins de carena (camins que també servien per als ramats) que els que seguien els fons de les valls i els congosts. Crida l'atenció, per exemple, que el camí d'accés a la Cerdanya venint de Ripoll, en lloc de seguir el curs del riu Freser, travessar la vall de Ribes i arribar fins a la collada de Toses, preferís enfilar-se per la dreta del riu Merdàs i, sempre fent solana, passar pel costat de l'església de Sant Pere de Mogrony fins a Castellar de N'Hug, des d'on un camí arribava fins a la conca cerdana tot passant pel Pla d'Anyella.

${ }^{21}$ De fet, coincideix amb la teoria del caput, ben coneguda pels estudiosos anglesos del paisatge. Vegeu: M. AsTON, Interpreting the Landscape, Londres, 1985, pp. 32-36.

${ }^{22}$ Sobre aquest aspecte, vegeu la valoració que en fa Prim Bertran i Roigé, Notes sobre la ramaderia a la Catalunya nord-occidental (segles $I X-X I$ ). Primera part, "Ilerda", XLVII (1986), pp. 219-2?:1.

${ }^{23}$ Un precepte de l'any 982 diu: in civitate Limignana ecclesia Sancti Andreae cum alodibus. R. D'ABADAL, Els diplomes, p. 243. 
Un altre aspecte que ens ensenya l'estudi detallat, sobre un mapa, de les donacions fetes a un cert monestir és que de vegades sembla com si s'hi reflectissin diverses etapes de viatge, en relació amb els itineraris que havien de fer els monjos per a anar d'un lloc a un altre o, potser, que havien de seguir els ramats. El monestir de Camprodon, situat a l'extrem occidental del comtat de Besalú, posseïa força drets a la punta est d'aquest comtat, cap a Maçanet de Cabrenys i, entremig d'aquests dos indrets, tenia possessions a la vall de Carrera, a Montagut, a Pruneres, a Tortellà, etc. ${ }^{24}$

\section{F. CAmins i ROtLles mortuoris}

Un cas concret, que ens permet d'estudiar no sols els camins sinó també unes possibles etapes, el trobem als itineraris seguits pels rotlles mortuoris del segle XI i de molt als inicis del XII. Se n'han conservat, en relació amb Catalunya, en principi quatre: el de Sunifred, abat de Ripoll (100809), el de l'abat Oliba (1046-47), el del comte Guifre de Cerdanya (1051) i el de Bernat, abat de Ripoll (1102). ${ }^{25}$ Aquests rotlles mortuoris, que anaven passant de l'un monestir a l'altre, amb la funció que les diverses comunitats preguessin pel difunt, recorregueren extensos territoris d'Europa occidental. ${ }^{26}$ Certament, són força coneguts i estudiats; per això, ara sols ens cenyiren a l'itinerari que seguiren per Catalunya i intentarem d'aproximar-nos a la qüestió del temps que hom trigava en anar d'un lloc a un altre.

Cal assenyalar d'entrada que els itineraris seguits segurament eren força condicionats pels monestirs que hi havia. Amb tot, per exemple, el camí recorregut a Catalunya pel rotlle de l'abat Oliba és prou interessant: Arles (Vallespir), Sureda (Rosselló), travessa de la serra de l'Albera possiblement pel coll de Banyuls, Colera (Alt Empordà), Sant Pere de Rodes, Roses, Girona, Banyoles (Pla de l'Estany), Besalú, Sant Llorenç del Mont (Garrotxa), salta a Casserres (Osona) per la via que anava d'Olot a Vic -resta, però, el dubte que no passés per Camprodon-, Vic, segurament Sant

24 Vegeu: J. Bolos - V. Hurtado, Atlas Històric de Catalunya, fulls 10-1 i 11-1, Barcelona, 1984-1986.

25 Jean Dufour, Les rouleaux et encycliques mortuaires de Catalogne (1008-1102), "Cahiers de Civilisation Médiévale», XX (1977), pp. 13-48.

${ }^{26}$ El de Sunifred, abat de Ripoll, va recórrer uns $1.700 \mathrm{~km}$ i arribà fins a Charroux, al nord de la Gàl.lia; el de l'abat Oliba, uns $2.800 \mathrm{~km}$ i va atènyer, en els seus extrems, Marmoutier i Autun, a la França septentrional; el rotulus de Guifre, comte de Cerdanya, va fer uns 3.800 km i arribà fins a Aquisgrà i Mastricht; el de l'abat Bernat, de Ripoll, uns $2.400 \mathrm{~km}$, i arribà nins a Palència i La Reola, prop de Burdeus, i fins a Arles, a la Provença. Vegeu: Dufour, Op.cit. a la nota precedent. 
Llorenç del Munt (Vallès), Sant Cugat del Vallès, Santa Cecília de Montserrat (Bages), Sant Benet de Bages, Serrateix (Berguedà) i, passant pel Cardener o pel Llobregat, arribada a la Seu d'Urgell (Alt Urgell). Podem adonar-nos que, per motius de seguretat o potser, i més aviat, per seguir el camí més recte entre els diversos monestirs, no s'agafa la via de tradició romana que, com ja hem vist, passava entre el Montseny i el Montnegre. Via que, d'altra banda, surt prou ben documentada en aquesta època (stratam qui pergit de Gerunda ad Barchinonam) i que, molt possiblement, era una de les vies més importants que seguien els grans mercaders de l'època, tor $\mathrm{i}$ el perill que podia representar travessar la comarca de la Selva aleshores plena de boscs i d'aiguamolls. ${ }^{27}$

L'itinerari seguit pel rotlle del comte Guifre de Cerdanya és força semblant al precedent. A partir del monestir del Canigó, segueix el Vallespir, l'Empordà, entra al comtat de Besalú i després al de Vic. Salta al Vallès i, potser, finalment se'n va a Tavèrnoles, a l'Alt Urgell. Ens resta el dubte de situar les etapes de Camprodon i Ripoll al final de tot o bé entre les de Besalú i Vic.

Per acabar, l'itinerari de l'abat Bernat de Ripoll és força diferent: el rotlle se'n va de Ripoll a la Portella (Berguedà), a Cardona (Bages), a Organyà (Alt Urgell), a la Seu d'Urgell, a Gerri (Pallars), a Alaó (Ribagorça) i a Roda d'Isàvena, des d'on continua cap a l'oest. A la tornada sembla que passà per diversos monestirs del Conflent, el Vallespir i el Rosselló. En aquest cas, cal assenyalar l'existència, ben evident, d'una línia de comunicació transversal, paral.lela als Pirineus, la importància de la qual ja ha estat esmentada més amunt.

Un dels aspectes que també té força interès és saber el temps que trigaven d'anar d'un lloc a un altre. Per exemple, el dia 13 de maig, el rotlle de l'abat Oliba era a Rodes, el 14 a Girona, el 15 a Banyoles, el 18 a Besalú, el 21 a Vic, el 28 a Sant Cugat; el 3 del mes següent, a Serrateix i el 7, a la Seu d'Urgell. De fet, de vegades veiem que els qui portaven el rotlle anaven força de pressa, i unes altres vegades segurament s'estaven més d'un dia en un lloc. Pel que fa al rotlle del comte Guifre, veiem que tot l'itinerari per Catalunya fou fet en menys d'un mes. El 9 de març era a Sant Genís de Fontanes i el 2 del mes següent, a Tavèrnoles.

\section{G. FORTIFICACIONS I VIES}

El topònim la Clusa o la Clua, en principi, el podem relacionar amb una via de comunicació o amb un lloc de pas important. Trobem un prece-

27 Ramon D'ABADAL, Els diplomes carolingis a Catalunya, I, Barcelona, 1926-1950, p. 71. 
dent immediat d'aquest nom de lloc en l'organització castral d'època visigòtica $\mathrm{i}$ també potser un punt de referència coetani en l'organització que hi havia en les vies que travessaven els Alps. ${ }^{28}$

Al sud del Rosselló, prop del límit amb l'Empordà, hi ha el lloc anomenat les Cluses (o la Clusa), que ha estat relacionat amb les Clausuras d'època visigòtica que hi havia, en aquest indret, per on passava la Via Domitia o Via Augusta. ${ }^{29}$ Les clusas sembla que eren fortificacions que es feren, durant el domini visigòtic, en llocs de pas que calia defensar $i$ controlar. És normal que se'n construïssin unes en un lloc estratègic, com és prop del Portús, indret que, amb tot, no ho hem d'oblidar, només separava dues terres que depenien dels mateixos monarques gots. És interessant d'adonar-nos també que podem trobar algunes altres "cluses» o "clues» en el territori català. ${ }^{30} \mathrm{~A}$ la vall de la Noguera Ribagorçana, al nord del pas de Montrebei, prop dels castells d'Alsamora o de la Torre Girbeta, hi ha el lloc de la Clua de la Conca. A la vall de Meià, entre Vilanova de Meià i Artesa de Segre, hi ha la Clua de Meià. Damunt d'un revolt del riu Segre, entre Bassella i Tiurana, a la comarca de l'Alt Urgell, hi ha la Clua d'Aguilar. ${ }^{31}$ A l'Alt Berguedà, a l'est del riu Llobregat, a uns quants quilòmetres d'aquest riu, hi ha el lloc de Sant Romà de la Clusa. Finalment, la documentació també ha conservat l'existència d'una altra Clusa, situada a l'est de la comarca de Bages, al terme del castell de Rodors, prop de Moià. ${ }^{32}$

28 «Especial cuidado se prestó a la defensa de los pasos fronterizos de los Pirineos catalanes, donde se constituiría un potente distrito militarizado erizado de castillos en las principales rutas de paso, y a los que se dio el significativo nombre de clausurae». Luis A. GARCin MORENO, Historia de España visigada, Madrid, 1989, p. 332. Vegeu, per exemple, pel que fa als Alps: P. DuparC, Les cluses et la frontiere des Alpes, "Bibliothèque de l'École des chartes", CIX (1952). Encara als segles XI o XII, als Alps s'esmenten les Clusae Langobardorum i els senyors de les contrades properes rebien el nom de clusarii. Vegeu: Giuseppe SERGI, Potere e territorio lungo la strada di Francia, Nàpols, 1981, pp. 38 i 295.

29 Prop seu, segons estudis fets per Joan Badia, s'han trobat algunes altres fortificacions d'època visigòtica, semblants a les que hi havia en aquest indret: Catalunya Romànica, VIII, Barcelona, 1989, pp. 43-48.

30 El poble de la Clusa, al Rosselló, també rep el 1632 el nom de la Clua. Pere PONSICH, Limits histdrics $i$ repertori toponímic dels llocs babitats dels antics «Paiisos» de Rossell6Vallespir-Conflent-Capcir-Cerdanya-Fenolleda, Prada, 1980, p. 36.

${ }^{31}$ Cal tenir present que, seguint el riu Segre amunt, trobem a la seva riba dreta, davant d'on hi havia hagut el castell d'Oliana, l'indret de Castell-llebre, que correspon a un "Castell vedre" o castell vell. Aquest topònim ja surt documentat abans de l'any 1000 , fet que fa suposar que aquesta fortificació ha d'ésser d'un moment anterior al segle $\mathrm{X}$; o bé és de cap a l'any 800 o bé, més aviat, és d'abans d'aquesta data.

32 No podem descartar que en algun cas "clusa» hagi d'ésser, més aviat, relacionat amb clos, lloc tancat. En general, però, sol ésser considerat com un congost fortificat. Vegeu: $\mathbf{M}$. Bassols - J. BASTARdas et alii, Glossarium Mediae Latinitatis Cataloniae, Barcelona, 1969, cols. 523-526. 
Ens agradaria de cridar l'atenció principalment sobre el fet que tots, o gairebé tots, aquests indrets són col-locats en llocs estratègics, al costat de passos importants i prop del límit dels Pirineus. Aquest darrer fet segurament no és pas casual i respon a la necessitat de delimitar una zona pirinenca amb unes característiques de poblament especial; això, però, ja surt del marc d'aquest estudi. L'existència d'aquests topònims ens mostra, tanmateix, una pervivència, en un nom de lloc, d'una realitat segurament anterior a l'època carolíngia $\mathrm{i}$, així mateix, la importància que tenien alguns d'aquests llocs de pas en les comunicacions nord-sud, a l'alta edat mitjana.

Un altre aspecte que podríem tractar en aquest apartat, tot $i$ que no ho farem, és la relació, cap el segle $\mathrm{x}$, entre les principals vies de comunicació $\mathrm{i}$ la fortificació de les "marques» o fronteres dels comtats catalans. De fet, tot i que no puguem rebutjar la relació, abans de l'any 1000, entre camí i castell, per exemple al llarg de la via que seguia el Penedès, creiem que el castell termenat tenia, en primer lloc, el paper de centre i d'organitzador d'un territori, on hi havia un representant del comte $i$ uns pobladors que calia administrar.

\section{H. Camins, pobles I masos}

L'any 1967, W.G. Hoskins publicava el mapa d'una parròquia anglesa (Codbury, Devon) on situava tots els masos i la xarxa de camins que els comunicaven. ${ }^{33}$ Segons ell, aquesta xarxa de vies era del segle XI o d'abans. De fet, com veurem, podríem fer un mapa i unes afirmacions molt semblants a aquestes, en relació amb algunes parròquies de Catalunya, a on pel que fa a la xarxa viària a nivell local, bàsicament podem distingir dos models, d'acord amb el tipus d'hàbitat del lloc.

Un primer tipus el trobaríem en pobles d'hàbitat agrupat. Molt sovint, a partir d'un nucli central on hi havia el centre de poblament, sortien una sèrie de camins en les diverses direccions, radialment, per anar als diversos pobles de l'entorn. En podríem trobar nombrosos exemples. A cavall entre les comarques d'Urgell $\mathrm{i}$ de la Conca de Barberà, per exemple, els pobles de Rocallaura o de Belltall, estudiats darrerament, en són un bon exemple (vegeu mapa 2) ${ }^{34} \mathrm{Hi}$ havia un camí que unia aquests dos pobles veïns; a

${ }^{33}$ Els masos és una traducció de l'anglès farmsteads, tipus d'habitatge també de les zones d'hàbitat dispers. W.G. Hoskins, Fieldwork in Local History, Londres, 1982, p. 20.

34 Caterina ARgiLfs, Paisatge, societat i organització del territori a Rocallaura (Urgell) al segle XV, "Paisatge i societat a la Plana de Lleida a l'edat mitjana», Lleida, 1993. Jordi Bolos - Salvador Claramunt, El capbreu de la comanda de l'Espluga de Francolí del 1558, Barcelona, 1991 , p. 60 (per Belltall) o p. 65 (per la Guàrdia Lada). 
més, des de Rocallaura n'hi havia d'altres que anaven cap a Vallbona, Montesquiu, el Tallat, Solivella, etc. Així mateix, molts d'aquests camins permetien d'anar a les diverses partides de terres del terme; evidentment, si calia hi podia haver un altre camí per a anar als horts, a un bosc, a un santuari determinat, etc. Aquesta xarxa de camins ha de correspondre al moment de la conquesta d'aquests llocs, cap al segle XI, encara que alguns ja existien en una època anterior.

Pel que fa a les zones d'hàbitat dispers, una xarxa de camins comunicava els diversos masos, quasi d'una manera igual, tot i la distància que separa els dos països, que la que ens ensenyava Hoskins en relació amb Anglaterra. Una bona mostra d'això la trobaríem també a la parròquia de Serrateix, al Baix Berguedà (vegeu mapa 2), a la parròquia de Sant Esteve d'En Bas o a la de Montagut, a la Garrotxa, per citar alguns casos. Cal pensar que una bona part d'aquesta xarxa de camins i corriols es creà al mateix moment que es constituí la xarxa de masos; segurament, però, es desenvolupà en diverses etapes, atès que els llocs de poblament també aparegueren -i es transformaren- al llarg dels segles. Sigui com vulgui, podem coincidir amb Hoskins i datar, si fa no fa, molts d'aquests camins vers el segle XI, al voltant de l'any 1000 . Aquesta és, si més no, la data que hem proposat per a la constitució dels primers masos dispersos. ${ }^{35}$

Això és així en principi. És cert, però, que en molts casos hi ha elements distorsionadors, com el fet que passi una via important pel mig del terme. Això, en zones de poblament escampat, pot fer que es desenvolupi una xarxa de camins ramificada a partir d'un eix anterior al desenvolupament de les cases. En zones d'hàbitat agrupat, pot arribar a fer que el camí més important passi per fora del poble. Si ens fixem en la xarxa de comunicacions a l'Empordà, veiem que l'antiga Via Augusta d'època romana talla la plana, independentment de la xarxa de vies que uneixen els diversos pobles i que segurament tenen origen a l'alta edat mitjana. ${ }^{36}$

També cal tenir present que en molts indrets hi hagué, en algun moment de la història, un hàbitat semiconcentrat. En aquest cas, els vilars o poblets que hi havia pogueren tenir el mateix paper central que tenien els pobles, a les zones d'hàbitat apinyat $o$, en certa manera, el que tenien els masos, a les zones de poblament espars.

35 Jordi Bolos, El mas, el pagès $i$ el senyor (en curs de publicació).

36 Vegeu: Josep CASAS I GenOver, Les vies de comunicació romanes al Pirineu Català orien-

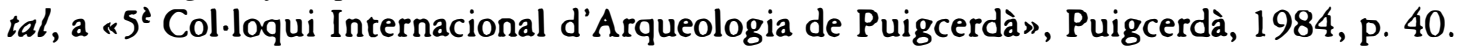




\section{Camins I límits Parroquials}

L'estudi de les parròquies $i$ en especial dels límits que tenien, ens pot aportar força informació sobre els camins medievals. Fixem-nos en uns quants exemples:

La parròquia de Granollers de la Plana, segons l'acta de consagració de l'any 1088, tenia diverses afrontacions que coincidien amb vies de comunicació: el caminum de Goncero, una stratam franciscam, la strata que vadit ad Rivumpullum, etc. ${ }^{37} \mathrm{~A}$ Palau-solità, d'acord amb l'acta de consagració del 1122, les afrontacions parroquials eren la strata que pergit de Petrafita de Calidis ad Barcinonam, una altra viam que pergit per serram de Plegamans $\mathrm{i}$ encara una via publica que pergit per Serra de Macerata (de Can Marata). ${ }^{38}$ Les afrontacions de la parròquia de Reixac (1048), entre d'altres, eren ipsam stratam publicam quam itur in parte Romae de Hispaniae i una altra strata, a part de rius, torrents, serres, puigs i pedres. ${ }^{39}$

Uns darrers exemples. Un dels límits de la parròquia de Merlès era: strata Bergitanense qui pergit ad Osona. ${ }^{40} \mathrm{En}$ uns altres casos, veiem que coincideixen les vies amb serres: a Manlleu, el 906, trobem: strada que pergit per serram. ${ }^{41}$ En relació amb la parròquia de Santa Eugènia de Berga, del 1173 , trobem que s'esmenten viam, stratam, semitam, etc. ${ }^{42}$

A partir d'aquests exemples ens podem plantejar diverses coses: ¿què hi hagué abans, el límit o bé la parròquia? Això ens portaria a un estudi diferent sobre l'origen dels termes parroquials. ${ }^{43} \mathrm{Hem}$ de tenir present, com hem dit, que moltes d'aquestes vies tenien l'origen en època romana, fet que fa pensar que són anteriors als límits parroquials. D'altra banda, però, també hem proposat en un altre estudi, que molts termes parroquials coincideixen amb termes de pobles o de comunitats rurals o amb dominis senyorials anteriors al moment en què es crearen les parròquies, la major part de les quals són d'època carolíngia. Sigui com vulgui, segurament, moltes vegades, hi hagué abans els camins i després s'establiren els termes.

37 Catalunya Romànica, II, Barcelona, 1986, p. 216.

38 Catalunya Romànica, XVIII, Barcelona, 1991, p. 128.

39 Catalunya Romànica, XVIII, Barcelona, 1991, p. 126.

40 Cebrià Baraut, Set actes més de consagracions d'esglésies del bisbat d'Urgell (segles IX-XII), "Urgellia», II (1979), pp. 484-485.

${ }_{41}$ Catalunya Romànica, II, Barcelona, 1986, p. 316.

42 Catalunya Romànica, III, Barcelona, 1986, p. 545.

43 Jordi Bolos, Parròquia i organització del territori. Una aproximació cartogràfica, "I Congrés d'Història de l'Església de Catalunya» (en curs de publicació). 


\section{J. CAMins I PARTIONS DE CAMPS}

Un tant per cent molt notable de les peces de terra que trobem a la documentació dels segles $\mathrm{X}$ i XI té com una de les afrontacions un camí, una via o una estrada. En general s'acosta a un $50 \%$. A Vallfogona de Ripollès, lloc en relació amb el qual hi ha un bon gruix de documents, ja fa temps vàrem calcular que un $43,5 \%$ de les terres comprades o donades tenia almenys, com una de les partions, una via de comunicació. El mateix càlcul aplicat a terres d'altres comarques, ens dóna tants per cents semblants. A la Plana de Vic, si agafem un conjunt de documents de la primera meitat del segle $\mathrm{X}$ trobem que el $55 \%$ de les peces de terra tenien una afrontació amb una via, una estrada o un sender ${ }^{44}$ Així, per exemple, una terra, esmentada en un document de l'any 904, situada al comtat d'Osona, a la vall de Santa Eulàlia, al lloc anomenat Torroella, afrontava a l'orient amb una via, al sud amb una estrada, a l'occident la una terra d'un particular i al nord amb una estrada. ${ }^{45}$ És, de fet, la mostra d'un cas extrem.

Aquest tant per cent tan elevat de coincidències entre afrontacions $\mathrm{i}$ vies de comunicació, podríem relacionar-lo amb la necessitat de poder accedir amb facilitat als camps. Segurament, però, no sols és això, ja que moltes vegades trobem com a afrontació vies o estrades força importants. També podem pensar que algunes vegades els camps de conreu es feien i es rompien, precisament en llocs on hi havia camins o a partir d'aquests camins. ${ }^{46}$

\section{K. CAMins I MEMBres D'UnA CONFRARia}

Ara volem centrar la nostra atenció en un document molt notable, de l'any 1100 , publicat per Serra i Vilaró. ${ }^{47}$ De fet, és prou conegut que les muntanyes no eren pas cap obstacle infranquejable, com es desprèn del que hem dit més amunt; tanmateix, és interessant aquest exemple que ens permet de veure-ho més clar $\mathrm{i}$ adonar-nos de la mobilitat que tenia la gent, en aquella època reculada. Ens interessa de conèixer l'àrea d'influència d'un lloc determinat, Lillet, indret que, malgrat ésser el centre d'una vall, no tenia un pes polític o administratiu gaire gran (tot i que hi havia la canònica de Santa Maria).

44 Jordi Bolos, Camí de Vallfogona, "Catalunya Romànica", X, Barcelona, 1987, pp. 449-450. Pel que fa a Osona: Eduard JUnYent i SubirA, Diplomatari de la catedral de Vic. Segles IX-X, Vic, 1980-1984.

45 Eduard JUNYENT, Op.cit., doc. 36.

46 Jordi Bolos, Aportacions al coneixement de les vies, p. 429.

47 Joan Serra I Vilaro, Baronies de Pinós i Mataplana, I, Barcelona, 1930, pp. 41-43. Publicat també a: Catalunya Romànica, XII, Barcelona, 1985, p. 360. 
Els membres de les famílies que signen la confraria cal suposar que eren, almenys en part, de la Pobla de Lillet; potser corresponen a una part dels 260 noms (el $59 \%$ del total, trets els eclesiàstics) que no van acompanyats d'un topònim. Pel que fa als que anaven acompanyats d'un topònim, n'hi havia uns 29 (corresponen a 19 llocs diferents) que eren gent del terme de Lillet (segurament no del poble). Aquests es relacionen amb noms de masos o veïnats com Ventaiola, Montclús, Vallfogona, Aièits, Puig, les Uncies, Muga, Falgars, Coromina, Arderiu, Sarga, etc. (vegeu mapa 3). A més, 23 persones o famílies més (corresponen a 17 llocs diferents) duen un nom d'un lloc de l'Alt Berguedà, alguns de pobles força propers, com Rus, Pardinella, Garravós (llavors Gavarret), Castellar de N'Hug, Sant Julià de Cerdanyola, Brocà, la Clusa, etc. Encara n'hi ha 10 (7 llocs) en què el nom de fonts va acompanyat d'un topònim del Ripollès, especialment de la zona occidental de la comarca: Espluga, Puigbò (aleshores Puigmal), Mataplana, Gausags, Estiula, etc. Finalment, hi ha 5 noms (en relació a 3 llocs) que, amb força seguretat, pertanyen a persones de la Cerdanya; són d'Oceja, de Das i de Tartera. A part de tots aquests noms de lloc, resten 13 topònims (que corresponen a 14 noms) sense localitzar.

Amb aquest exemple ens adonem de les relacions estretes que tenia un poble com la Pobla de Lillet amb els pobles de l'entorn, situats tant a les comarques actuals del Berguedà com del Ripollès. De fet, aquest tipus d'estudis de relacions familiars i de moviment de la gent normalment no se solen poder fer fins als darrers segles medievais, tot i que, arran del procés de repoblació de la plana de Lleida, per exemple, del segle XII, ja podem veure, gràcies a l'existència d'un cognom, la possible procedència de molts dels repobladors d'aquelles terres. ${ }^{48}$

A més, amb aquesta llista de noms de persones que eren part d'una confraria, on consten alguns habitants de l'altra banda de la serralada del Cadí-Moixeró-Tossa d'Alp, ens adonem també de l'existència d'unes relacions estretes entre Osseja, Das o Tartera i la vall de Lillet, per exemple a nivell familiar. Ens adonem que el límit de les muntanyes no representa un obstacle gaire gros, tot i que, ben segur, a l'hivern devia ésser difícil de travessar-lo. Cal recordar també que, a l'alta edat mitjana, totes les terres situades immediatament al sud de la serralada del Cadí-Moixeró-Tossa d'Alp depenien directament dels comtes cerdans; el comtat de Berga no començava fins al sud de la vall de Brocà-Lillet. ${ }^{49}$

48 Vegeu, per exemple: Josep LladonOSA, Història de Lleida, Tàrrega, 1972; Jordi Bolos, Paisatge i societat al «Segrià» al segle XIIl, a "Paisatge i societat a la Plana de Lleida a l'edat mitjana», Lleida, 1993.

49 Vegeu: Atlas Històric de Catalunya, full 10-2 i J. Bolos - V. HurTado, Notes històriques del Ripollès els segles IX $i$ X, "Quaderns d'estudis medievals», 4 (1981), pp. 209-218. 


\section{VIES I ANTROPONIMS}

Actualment hi ha en curs de publicació un repertori d'antropònims catalans d'abans de l'any 1000, en el qual col-labora J. Moran i publicat per I'IEC $^{50}$. Fins i tot un aspecte que, a primer cop d'ull, pot tenir tan poca relació amb les vies de comunicació com els noms de persona, en realitat, com acabem de veure-ho ara, ens pot aportar una informació interessant. Certament, hi ha una relació estreta entre les vies més importants i les migracions que hi hagué durant els segles VIII-X, relacionades, en bona part, amb el repoblament de les zones ocupades i reorganitzades pels monarques francs o pels comtes cristians.

Només volem posar dos exemples per a mostrar dues vies o camins de pas importants, no sols medievals, sinó gairebé de totes les èpoques, des la prehistòria:

-Via de la costa. Si agafem, per exemple, els noms que duien els habitants de Vilamacolum, a l'Empordà, l'any 913 , ens adonem que hi havia unes coincidències força notables amb noms de persones, per exemple, del Rosselló (antropònims com Segarius, Borracio, Godfortes). I no sols això. En general, hom s'adona que hi havia també moltes coincidències amb antropònims duts per gent de tota la zona propera al litoral, des de Barcelona fins, anant cap al nord més enllà del Rosselló, cap al Llenguadoc i la Provença. Així ho observem en noms com Vincemalus, Primio, Savilde, Polemia, Virgilio. En alguns casos, en certa manera, aquesta unitat antroponímica pot provenir d'una romanització més profunda; però, també, tenint present l'evolució normal del conjunt de noms de persona en aquells segles, això ha de derivar d'una perduració dels lligams i dels contactes entre totes aquestes terres properes a la costa. Això ho podem assenyalar, per exemple, en relació amb el nom de Virgilio i també, per exemple, pel que fa a l'antropònim Flavio, documentat a Bàscara, l'any 921. Aquest lligam de les poblacions del litoral també arriba, en certs aspectes, fins al Vallès, tot $i$ les influències pirinenques que, com direm tot seguit, sembla que va tenir aquesta comarca. El nom Sisoigia, que trobem a la Roca del Vallès, l'any 932, pot ésser inclòs en aquest grup d'antropònims de la Catalunya del litoral.

-Via del Conflent, la Cerdanya i l'Alt Urgell. Si agafem noms de persones de la Cerdanya i els relacionem amb els trobats en altres comarques catalanes, ens adonem de l'existència de nexes, per exemple, amb el Conflent i el Rosselló. Així, hi ha coincidències que no creiem pas que puguin ésser casuals, en persones que portaven el nom Alafredo, Naiero,

so Jordi Bolos - Josep MORAN, Repertori d'Antropònims Catalans. Segles IX-X, Barcelona (en curs de publicació). 
Ermenesclo, etc., que documentem tant al comtat cerdà com a la vall del Conflent. En alguns casos, com en el nom d'Alafredo, també el trobem al comtat d'Urgell. En aquest sentit, és interessant el lligam que hi havia entre uns habitants d'un poble de l'Alt Urgell anomenat "Vila Novella", esmentats l'any 873 , i els noms de pobladors d'aquesta mateixa època del Conflent (en relació amb antropònims com Redenaldes, Bunnoni, Wulgarelle, etc.). ${ }^{51}$

A aquestes dues grans vies de comunicació, evidentment, n'hi podríem afegir algunes altres, com per exemple l'eix que anava del Ripollès al Vallès, passant per Vic, ja esmentat per R. d'Abadal i estudiat per G. Feliu, el del Llobregat, el de Vic-Manresa-Anoia etc. ${ }^{52}$

Per acabar, només ens cal dir que, amb aquestes ratlles, hem intentat de fer diverses aproximacions a les vies de comunicació $\mathrm{i}$ a diferents maneres d'estudiar-les. Una bona part d'aquestes mostres són fruit de treballs de recerca realitzats aquests darrers anys $i$, d'una manera especial, de la realització de l'Atlas Històric de Catalunya. Anys 759-992, que cal recordar que, en un moment inicial, havia d'ésser tan sols un mapa de les vies de comunicació. En la realització d'aquest atles anem treballant des de fa més de deu anys. Acabada una primera etapa d'aquesta obra, que ens ha permès de publicar els fulls de Ripoll-Olot, de Figueres i de Blanes, ara hem entrat en una nova etapa que ens ha de permetre aviat editar-ne la continuació, amb unes característiques, però, una mica diferents. p. 78.

31 Jordi Bolòs, Antropònims i poblament, "Catalunya Romànica», VI, Barcelona, 1992,

32 Gaspar FeuU, Sant Joan de les Abadesses i el repoblament del Vallès, "Miscel-lània Fort i Cogul", Montserrat, 1984, pp. 129-135. 


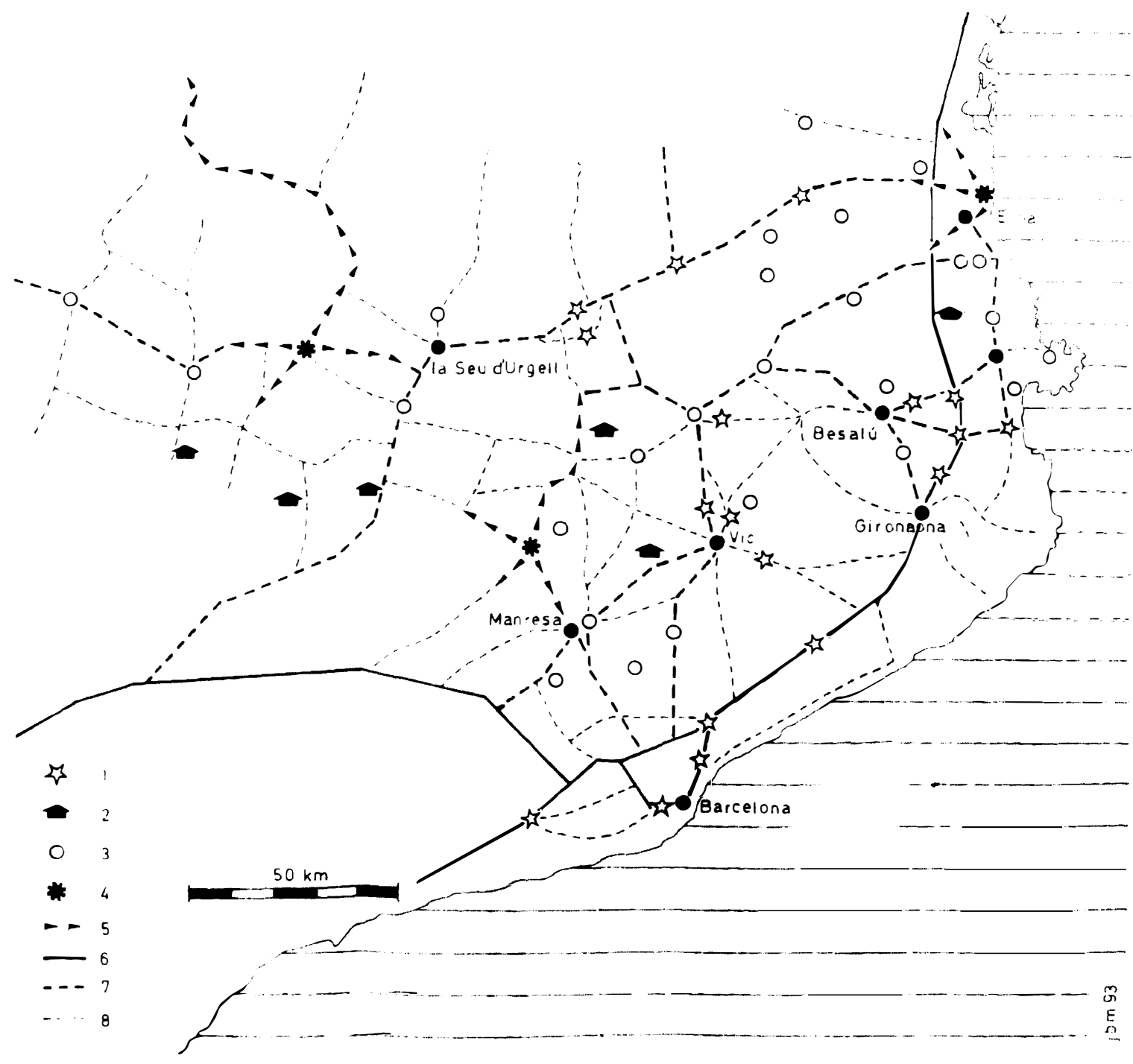

1. Mapa de les principals vies de comunicació terrestre a la Catalunya Vella a l'alta edat mitjana.- 1 . Indret on hi ha un esment, a la documentació, d'una via o estrada francisca.- 2. Existència d'un topònim Clusa 0 Clua.- 3. Monestir, priorat o canònica esmentats en alguns dels quatre rotlles mortuoris que s'han conservat.- 4. Lloc on es produïa sal (Gerri, Cardona i la costa rossellonesa).- 5. Via per on es transportava la sal (en relació amb Cardona, estrades cardoneses).- 6. Via molt important de comunicació, de tradició romana (bàsicament via domitia i via augusta).- 7. Via important de comunicació.- 8. Altres vies. 


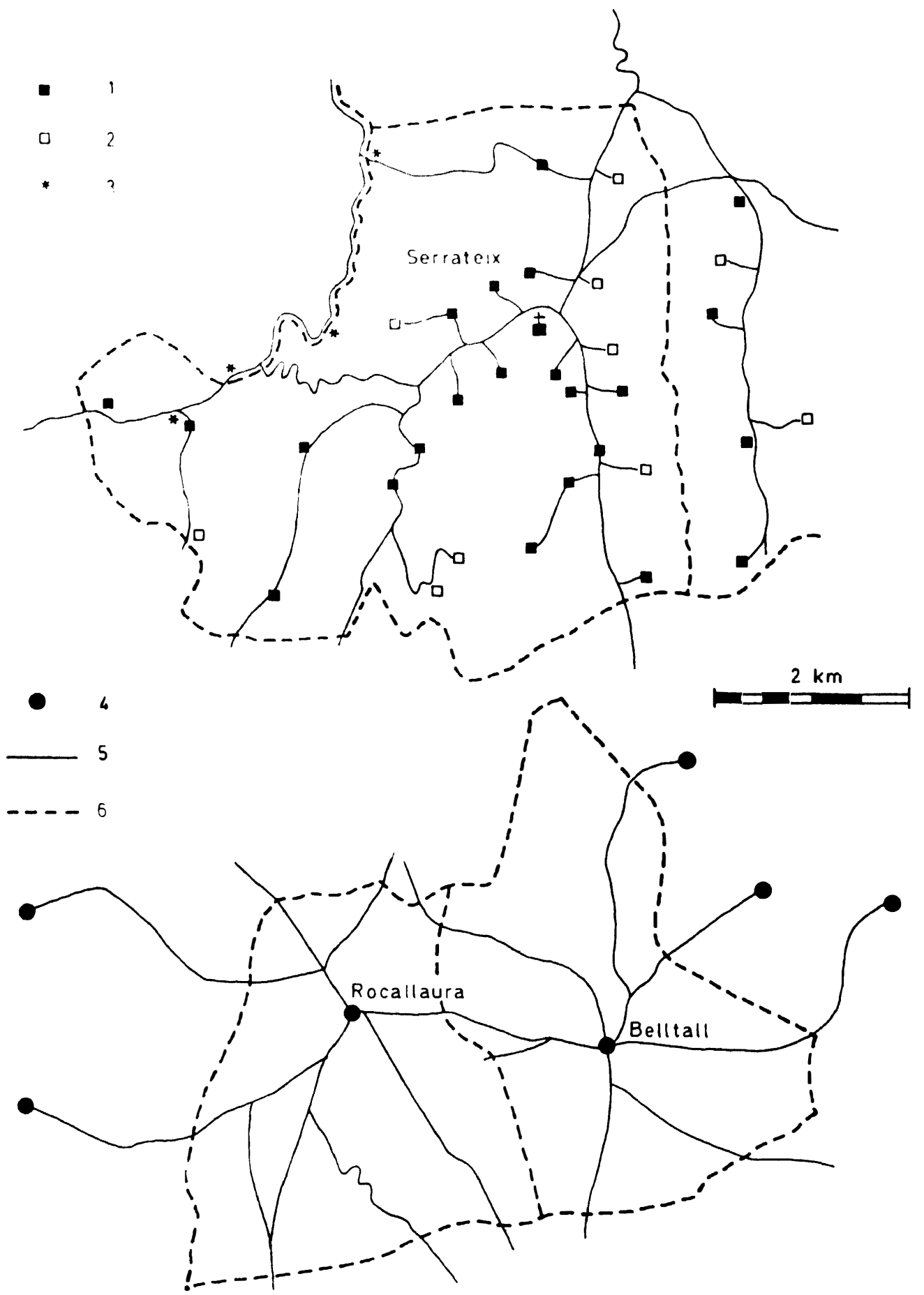

2. Camins i termes de poble. Dos exemples: Serrateix (Berguedà), a l'anomenada Catalunya Vella on hi ha un hàbitat dispers, i Rocallaura (Urgell) i Belltall (Conca de Barberà), a la Catalunya Nova, amb un poblament concentrat. 1. Mas documentat a l'edat mitjana.- 2. Mas que existia el segle passat i que possiblement també existia en època medieval.- 3. Molí.- 4. Poble, lloc de poblament agrupat.- 5. Camí.- 6. Límit de terme parroquial o municipal. El nord és a la part superior del mapa. 


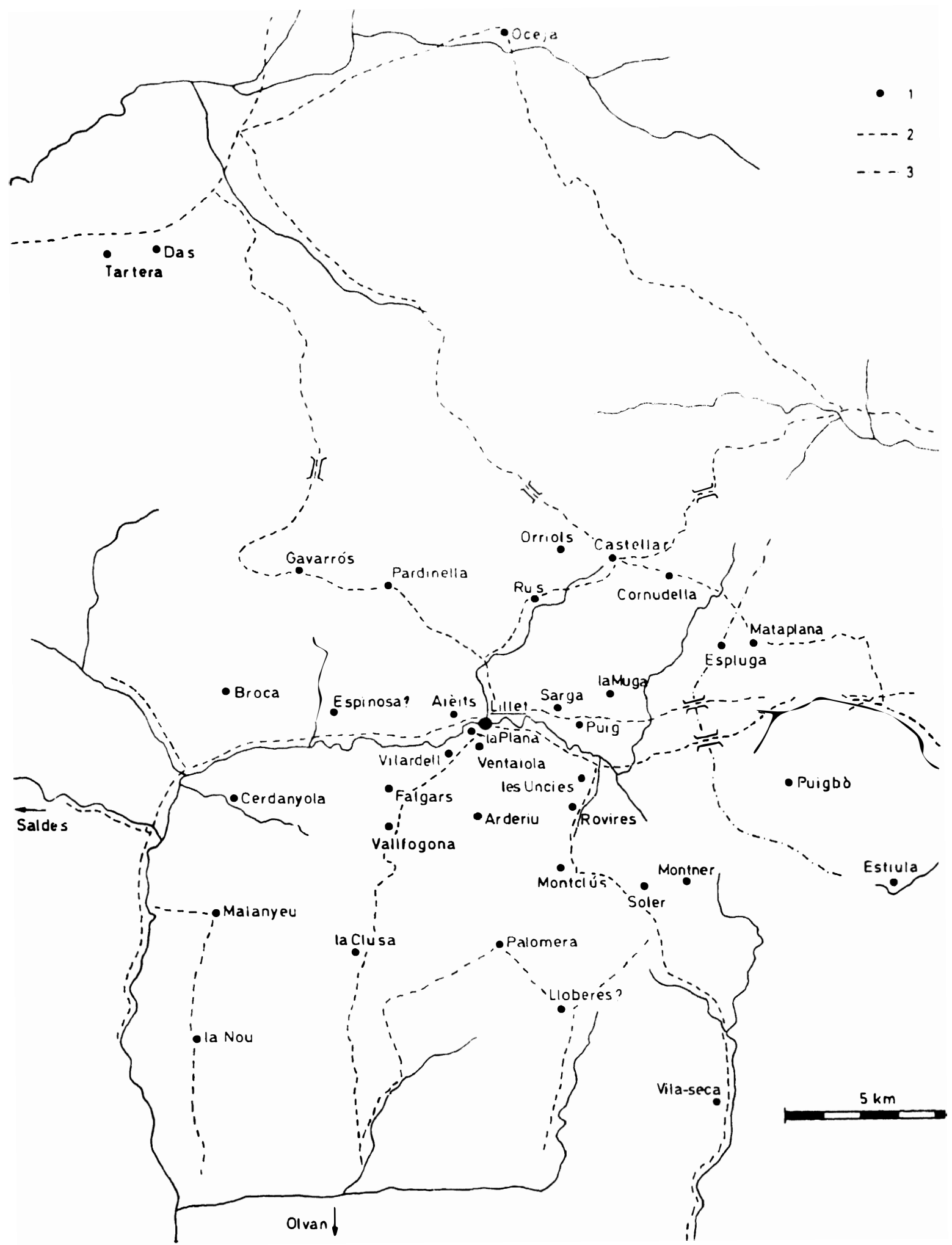

3. Procedència dels membres de la confraria que es constituí l'any 1100 a Lillet. 1. Lloc de poblament.- 2. Camí.- 3. Carrerada o camí per al bestiar. El nord coincideix amb la part superior del mapa. 


\section{RÉSUMÉ}

Après avoir exposé quels étaient les principaux types de voies existant entre le $\mathrm{IX}^{\text {eme }}$ et le XII ${ }^{\text {eme }}$ siècles et les principales caractéristiques de ces chemins, les auteurs tentent d'aborder ce que l'on sait au sujet des différents aspects du réseau de voirie du Haut Moyen-Age en Catalogne. Cela se fait à partir de l'analyse des sources diverses et presque toujours grâce à l'aide complémentaire de la cartographie. Les auteurs font mention de voies qui portent des noms différents (vies francisques, vies cardoneses, etc.) et parlent aussi des chemins les plus importants en relation avec les marchés de l'époque et l'activité mercantile. De même, ils rattachent l'existence des voies à la répartition des domaines monastiques, aux itinéraires que suivaient ceux qui portaient les clochettes mortuaires, à l'existence de fortifications des premiers siècles médiévaux (les cluses) et à la manière dont s'organisait le peuplement dans les différents villages. Ils essaient aussi de mieux connaître les caractéristiques et l'ancienneté des chemins à l'aide des limites des paroisses, des affrontements au sujet de terrains, de la distribution, sur un territoire donné, des lieux où vivaient les membres d'une confrérie et finalement à travers l'analyse des caractéristiques et de la répartition des patronymes avant l'an 1000 .

\section{SUMMARY}

We shall first expose which were the main types of roads that existed from the $\mathrm{X}^{\text {th }}$ till the $\mathrm{XII}^{\text {th }}$ century and the principal characteristics of those roads. Afterwards, the authors focus their attention on several aspects of the road network during the high Middle Ages in Catalunya, taking as a starting point the analysis of different sources and, nearly always, thanks to the complementary help of cartography. Refference is made to the existence of roads, that take different names: vies francisques, vies cardoneses, etc. and to the most important paths to the markets of that time, and commercial activities, in general, are listed. Thus the existence of roads is related to the distribution of monastic properties, to the ways followed by those who wore funeral bells, to the existence of fortifications of the first medieval centuries (the cluses) and to the way of organising the population in the different villages. We also try to learn more about the characteristics and age of the roads through the study of the limits of parochial districts, through confrontations about properties, through the distribution, in a territory, of the places where members of a brotherhood used to live and, even, through the analysis of the characteristics and distribution of anthroponyms before the year 1000 . 